\title{
Yersinia infection with Clostridium difficile colitis
}

\author{
M.J. Fishman, MD, M.A. Noble, MD, FRCPC, H.J. Freeman, MD, FRCPC, FACP
}

ABSTRACT: Antibiotic associated diarrhea appears to be largely due to Clostridium difficile and may have, at least in part, a toxin mediated pathogenesis. Because a poor correlation exists between measurable toxin titres and symptoms, additional copathogenic factors may be important. All patients seen during a two year period with diarrhea within four weeks of antibiotic therapy, a positive stool culture for $C$ difficile and a positive stool cy totoxin assay specific for $C$ difficile were investigated. All patients had stools cultured for enteric bacterial pathogens including Salmonella, Shigella, Campylobacter, Aeromonas and Yersinia species. Seven patients had Yersinia species isolated during the course of their illness; no other enteric pathogens were identified. In four patients, Y enterocolitica was cultured simultaneously with C difficile prior to treatment, and in one of these, $Y$ fredriksenii was also isolated. Of six patients with persistent or recurrent symptoms after treatment for $\mathrm{C}$ difficile (ie, vancomycin in five and metronidazole in one patient), four had positive yersinia cultures at the conclusion of therapy ( $Y$ enterocolitica in three and $Y$ fredriksenii in two patients). All but one of these patients had been yersinia culture negative prior to therapy for $\mathrm{C}$ difficile. Patients with and without yersinia isolates were then compared with respect to age, sex, clinical symptoms and sigmoidoscopic as well as rectal biopsy findings. The presence of yersinia was associated with male sex, younger age and abdominal pain; other features including hematochezia, fever, arthralgia, cytotoxin titre, sigmoidoscopy and rectal biopsy could not distinguish patients with and without Yersinia species. Thus, yersinia may be associated with an antibiotic related diarrheal illness usually attributed to $C$ difficile alone and may be observed in the setting of persistent or recurrent symptoms following treatment for $\mathrm{C}$ difficile diarrhea. Can J Gastroenterol $1989 ; 3(1): 21-25$

Key Words: Antibiotic diarrhea and colitis, Clostridium difficile, Clostridium difficile cytotoxin, Pseudomembranous colitis, Yersinia diarrhea, Yersinia entercolitica

\section{L'infection à yersinia et la colite attribuable à Clostridium difficile}

RESUME: Les diarrhées associées aux antibiothérapies semblent surtout attribuables à Clostridium difficile et pourraient présenter, en partie tout du moins, une pathogenèse liée aux toxines. Parce qu'il existe une faible corrélation entre les titres de toxines mesurables et les symptômes, les facteurs co-pathogènes supplémentaires sont peutêtre importants. Ont été examinés: tous les patients-(14) vus sur une période de deux ans et souffrant de diarrhées moins de quatre semaines après une antibiothérapie, et ayant subi un coproculture destinée à repérer $C$ difficile avec résultats positifs. Pour

Departments of Medicine (Gastroenterology) and Pathology (Medical Microbiology), University of British Columbia and the University Hospital. Vancouver, British Columbia

Correspondence and reprints: Dr Hugh Freeman. Head, Gastroenterology, ACU F-137, University Hospital (UBC Site), 2211 Wesbrook Mall, Vancouver, British Columbia V6T 1W5. Telephone (604) $228-7216$

Received for publication June 17, 1988. Accepted October 7, 1988

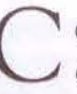

OLITIS MAY COMPLICATE ANTIMIcrobial therapy and, in the vast majority of patients, appears to be due to Clostridium difficile (1). In most cases, treatment with oral vancomycin is effective although one or more symptomatic relapses may occur (1). Failure to eradicate the organism, possibly due to sporulation, or acquisition of a new strain of C difficile, may be responsible (2). Alternatively, coinfection with another organism or acquisition of a second organism could occur.

In the present study, all patients seen in the hospital during a two year period with C difficile associated colitis were evaluated prior to and at the conclusion of therapy for a second bacterial pathogen or parasite. In this specific setting, a significant proportion of patients with disease initially attributed to $\mathrm{C}$ difficile were observed to have Yersinia species infection, but no other, bacterial pathogens.

\section{MATERIALS AND METHODS}

Specimen source: Fecal specimens were derived from inpatients being investigated for diarrhea or from patients referred to an outpatient clinic specializing in gastrointestinal diseases; a small number of specimens were submitted from a university student health service. During the two year period of this study, 403 stool specimens from 269 patients were cultured for $\mathrm{C}$ difficile and its cytotoxin; all stool specimens were routinely cultured for Yersinia species. A total of 14 patients were identified with diarrhea beginning within four weeks of antibiotic administration associated with a positive stool culture and cytotoxin assay for 
tous les patients, la mise en culture bactériologique a porté sur les agents pathogènes entériques - Salmonella, Shigella, Campylobacter, Aeromonas et Yersinia species y compris. Durant le cours de leur maladie, sept des patients étaient porteurs des espèces Yersinia et aucun autre agent pathogène n'a été identifié. Pour quatre patients, $Y$ enterocolitica et $C$ difficile ont été cultivés simultanément avant le traitement, et chez l'un deux, Y fredriksenii a été isolé. Chez six patients souffrant de symptômes persistents ou récurrents après avoir été traités pour $\mathrm{C}$ difficile (vancomycin chez cinq des patients et métronidazole pour l'autre), quatre ont donné des cultures positives pour la détection de Yersinia au terme de la thérapie ( $Y$ enterocolitica chez trois d'entre eux et $Y$ fredriksenii chez les deux autres). A l'exception d'un seul, tous ces patients avaient donné des résultats négatifs avant d'être traités contre $C$ difficile. Les patients chez qui Yersinia avait été isolé ou non, ont ensuite été comparés selon l'âge, le sexe, les symptômes cliniques et sigmoïdoscopiques, ainsi que d'après les résultats des biopsies rectales. La présence de Yersinia est associée aux patients de sexe masculin, d'un âge relativement plus jeune et souffrant de douleurs abdominales. Les autres caractéristiques incluent l'émission de selles sanglantes, la fièvre, l'arthralgie. Les titres de cytotoxines, les sigmoidoscopies et biopsies rectales ne sont parvenues à établir aucune distinction entre les malades atteints de divers types de Yersinia et les autres. Ainsi, Yersinia peut être associé aux diarrhées consécutives aux antibiothérapies que l'on a coutume d'attribuer à C difficile seulement et peut être détecté lors des symptômes persistants et récurrents qui se manifestent après le traitement des diarrhées provoquées par $\mathrm{C}$ difficile. La colite qui complique parfois les thérapies antimicrobiennes semble attribuable, dans la grande majorité des cas, à C difficile. Le plus souvent, un traitement à base de vancomycine par voie orale suffit, bien qu'une rechute symptomatique ou plusieurs puissent se produire. Si l'on ne parvient pas à éliminer l'organisme, il est possible qu'il y ait sporulation ou qu'une nouvelle souche de $\mathrm{C}$ difficile soit responsable de l'échec; ou encore, qu'il y ait co-infection par un autre organisme ou acquisition d'un second agent. Dans l'étude présente, qui porte sur une période de deux ans, tous les patients atteints d'une colite associée à $\mathrm{C}$ difficile ont été évalués avant et au terme d'une thérapie destinée à combattre un second agent pathogène ou parasite. Dans ce cadre particulier, un nombre significatif des patients atteints de maladies tout d'abord attribuées à $C$ difficile se sont avérés porteurs de Yersinia, mais d'aucun autre agent bactérien pathogène diarrhea in hospital and all were referred from within British Columbia. Stool specimens were obtained from all patients at the onset and conclusion of therapy for diarrhea presumed to be caused by $\mathrm{C}$ difficile infection. Specimens were submitted in containers with Cary-Blair port medium.

Culture media and processing: All specimens were routinely cultured on sheep blood agar (Prepared Media Laboratories, Tualatin, Oregon), McConkey agar (Difco, Detroit, Michigan), deoxycholate agar (Difco), thiosulphate-citratebile-sucrose agar (Oxoid, Basingstoke, UK), campylobacter agar (PML, Tualatin, Oregon), aeromonas agar (Difco) and selenite broth (Oxoid). Isolates of Escherichia coli were tested for their ability to ferment sorbitol as a screen for hemorrhagic colitis associated strains. Approximately $90 \%$ of the specimens were ac-
C difficile. Of these, no patient developed transport medium or fresh without trans- companied by additional fecal samples to examine for the presence of intestinal parasites. No fecal samples were examined for enteric viruses.

Yersinia culture and detection methods: Fecal material was streaked on yersinia selective (Schiemann CIN) medium (Gibso, Madison, Wisconsin) and incubated at $35^{\circ} \mathrm{C}$ for 18 to $24 \mathrm{~h}$ after cold enrichment intervals of $24 \mathrm{~h}$, three days and again after one and two weeks.

Yersinia species were first detected by their characteristic colonial morphology appearance on yersinia selection CIN medium. As described elsewhere (3), typical colonies have a 'bullseye' appearance with a deep cherry red centre and transparent margins. Colonies also have a ground glass appearance under the stereomicroscope and have a distinctive odour. Suspect yersinia isolates were further screened using a routine triple sugar iron agar slant for detection of glucose, lactose and sucrose fermentation or hydrogen gas production, as well as an urea slant for urease production. In addition, lysine and indole test reactions as well as motility after incubation at $28^{\circ} \mathrm{C}$ were assessed. Further confirmation of Yersinia series was done using an API 20E enterobacteriaceae system (API Laboratory Products Inc, St Laurent, Quebec), incubated at $28^{\circ} \mathrm{C}$. A typical group of sugar fermentation reactions for yersinia permitting initial distinction of the different species is tabulated in Table 1 . All positive isolates identified to species were submitted to an independent reference laboratory for confirmation as well as definition of biotype and serotype of the organism.

Clostridium difficile: $\mathrm{C}$ difficile was cultured anaerobically on CD and Columbia CNA media for $48 \mathrm{~h}$. (Capco Anaerobic Environmental System, Santa Clara, California). Identification was based on colonial appearance, typical 'barnyard odour, Gram stain morphology, aerobic and anaerobic subculture and anaerobic API sugar fermentation profile. Cytotoxin assay followed the method of Allen (4) using filtered stool supernatant $(10,000 \mathrm{~g} ; 0.45 \mu \mathrm{m}$ filter pore size), human foreskin fibroblast cultures and C difficile antitoxin (TD Wilkins, Virginia Polytechnic Institute, Blacksburg, Virginia). Titres were determined using serial 10 -fold dilutions of the supernatant.

\section{RESULTS}

Clinical features: Table 2 shows the age and sex of the 14 patients with $C$ difficile

\section{TABLE 1}

Typical sugar fermentation reactions of Yersinia species

\begin{tabular}{lcccc}
\hline Species & Sucrose & Rhamnose & Raffinose & Melibiose \\
\hline Yenterocolitica & + & - & - & - \\
Yfredriksenii & + & + & - & - \\
Yintermedia & + & + & + & + \\
Ykristensenii & - & - & - & - \\
\hline
\end{tabular}


TABLE 2

Clinical features

\begin{tabular}{lccc}
\hline Clinical feature & Negative & $\begin{array}{c}\text { Yersinia cultures } \\
\text { Positive } \\
\text { (before therapy) }\end{array}$ & $\begin{array}{c}\text { Positive } \\
\text { (after therapy) }\end{array}$ \\
\hline $\begin{array}{l}\text { Age (years) } \\
\text { Range }\end{array}$ & $24-89$ & $31-77$ & $27-77$ \\
$\quad$ Mean & 61 & 48 & 52 \\
Sex & 2 & 2 & 2 \\
$\quad$ Male & 5 & 2 & 3 \\
$\quad$ Female & $7(1)$ & $4(1)$ & $5(1)$ \\
Diarrhea (bloody) & 2 & 3 & 2 \\
Abdominal pain & 2 & 1 & 1 \\
Fever & 1 & 0 & 1 \\
Arthralgias & & & \\
\hline & & &
\end{tabular}

diarrhea. Yersinia species tended to occur in younger patients compared to the group with negative cultures. In addition, males were more often likely to have a positive culture.

Table 2 also shows symptoms elicited in the 14 patients with $\mathrm{C}$ difficile diarrhea. Inclusion criteria required the presence of diarrhea within four weeks of antibiotic therapy; one patient with bloody diarrhea had a negative yersinia culture, one had a positive initial culture and one with initially negative cultures, whose diarrhea became bloody after failed treatment, subsequently had yersinia isolated.

Abdominal pain or tenderness at the time of initial culture was more common when yersinia was present (three of four patients, $75 \%$ ) than when yersinia was absent (two of seven patients, 29\%). With failed therapy for $\mathrm{C}$ difficile, one patient had persistent abdominal pain and persistence of $Y$ enterocolitica in stool. In one patient with persistent diarrhea and initially negative cultures for yersinia, abdominal pain and the presence of both $Y$ enterocolitica and $Y$ fredriksenii developed after vancomycin therapy for $\mathrm{C}$ difficile. Duration of symptoms did not differ in yersinia positive patients compared to yersinia negative patients.

\section{TABLE 3}

Yersinia cultures in Clostridium difficile diarrhea

\begin{tabular}{lcc}
\hline Species & $\begin{array}{c}\text { Culture positive } \\
\text { before treatment }\end{array}$ & $\begin{array}{c}\text { Culture positive } \\
\text { after treatment }\end{array}$ \\
\hline Yenterocolitica & 4 & 3 \\
Biotype 1. Serotype 0:41 & 1 & 0 \\
Biotype 1. Serotype 0:6,30 & 2 & 1 \\
Nontypeable & 2 & 2 \\
Yfredriksenii & 1 & 2 \\
Yintermedia & 0 & 1 \\
\hline
\end{tabular}

in three patients and $Y$ fredriksenii in two (isolated concurrently with Yenterocolitica in one patient). Only one patient with $Y$ enterocolitica had been yersinia culture positive prior to treatment. One further patient with a positive $Y$ enterocolitica culture at the onset of treatment for diarrhea became asymptomatic after vancomycin therapy. However, a repeat stool culture after 16 days of treatment revealed $Y$ intermedia; in this patient neither $\mathrm{C}$ difficile nor $Y$ enterocolitica could be identified following treatment. No other enteric pathogens were isolated at any time during the illnesses of these 14 patients.

Sigmoidoscopic and biopsy findings: Flexible fibreoptic sigmoidoscopy with biopsy was done in all 14 patients at the onset of symptoms and was repeated in all patients with failed therapy (Table 4). The endoscopic and histologic observations did not differentiate patients with yersinia isolated in stool cultures compared to patients without positive cultures. The patient with persisting $Y$ enterocolitica before and after treatment has a 'nonspecific' colitis histologically confirmed at both times with positive cultures.

\section{Clostridium difficile cytotoxin titres:}

Table 5 shows $\mathrm{C}$ difficile cytotoxin titres in patients with and without positive yersinia isolates. No differences in toxin titres were observed. All four patients with persistent diarrhea and positive yersinia cultures after therapy had C difficile cy totoxin titres measured; all of these patients had negative cytotoxin assays after therapy. Two other patients with persistent symptoms following treatment had negative yersinia cultures; one of these patients had a persistently positive $\mathrm{C}$ difficile stool cytotoxin assay (titres of $1 / 10,000$ before and after a course of vancomycin therapy).

\section{DISCUSSION}

Several organisms have been etiologically implicated in post antibiotic colitis. Staphylococcus aureus received much attention initially (5) and, more recently. C perfringens has been suggested as a possible cause (6). However, the majority of cases are presently ascribed to $\mathrm{C}$ difficile. $\mathrm{C}$ difficile produces an enterotoxin (ie, toxin $\mathrm{A}$ ) and a potent cytotoxin (ie, toxin 
TABLE 4

\section{Sigmoidoscopic and biopsy findings}

\begin{tabular}{lccc}
\hline Pathology features & Negative & $\begin{array}{c}\text { Yersinia cultures } \\
\text { Positive } \\
\text { (before therapy) }\end{array}$ & $\begin{array}{c}\text { Positive } \\
\text { (after therapy) }\end{array}$ \\
\hline $\begin{array}{l}\text { Performed } \\
\text { Pseudomembranous }\end{array}$ & 7 & 4 & 4 \\
$\quad$ colitis & 3 & 1 & 2 \\
Aphthoid ulceration & 1 & 0 & 1 \\
Nonspecific diffuse colitis & 2 & 2 & 1 \\
Normal & 1 & 1 & 0 \\
\hline
\end{tabular}

TABLE 5

\section{Clostridium difficile cytotoxin titres}

\begin{tabular}{lccc}
\hline Titre & Negative & $\begin{array}{c}\text { Yersinia cultures } \\
\text { Positive } \\
\text { (before therapy) }\end{array}$ & $\begin{array}{c}\text { Positive } \\
\text { (after therapy) }\end{array}$ \\
\hline $1 / 100$ & 3 & 2 & 4 \\
$1 / 1000$ & 3 & 0 & 0 \\
$1 / 10.000$ & 1 & 2 & 1 \\
\hline
\end{tabular}

B) (7-9). The cytotoxin may induce typical changes in the colonic mucosa (8) and its detection has been used to establish the diagnosis (1). However, there appears to be a poor correlation between cytotoxin titre (toxin B) and the severity of the clinical illness (10). Although toxin A may correlate more strongly with symptoms, other factors may also be involved (11).

Of 108 patients with post antibiotic $C$ difficile colitis in Sweden, none had other enteric pathogens isolated; some patients, however, had detectable cytotoxin but negative cultures for $\mathrm{C}$ difficile (12). This raised the possibility of $\mathrm{C}$ difficile cytotoxin production by undetected organisms, perhaps other than $\mathrm{C}$ difficile (12, 13). Bartlett (14) has reported that five of 144 patients with significant titres of $\mathrm{C}$ difficile cytotoxin had negative cultures; attempts to identify other organisms in such circumstances were unsuccessful. In contrast, other studies have indicated that more 'traditional' pathogens such as Salmonella and Campylobacter species may be isolated from patients with $\mathrm{C}$ difficile. Culture techniques and/or, possibly, geographic factors may have accounted for the unusually high frequency of yersinia in seven (or $50 \%$ ) of the present patients with $\mathrm{C}$ difficile diarrhea. Post antibiotic colitis due to $Y$ enterocolitica in the absence of $\mathrm{C}$ difficile has also been reported (17). Finally, three patients with $Y$ enterocolitica associated diarrhea have been described with $C$ difficile cytotoxin also detected (3).

Administration of antibiotics in the month prior to positive stool culture was previously noted in 29 of 122 patients with $Y$ enterocolitica associated diarrhea (3). The role of antibiotics in predisposing to coinfection with Yersinia species and $\mathrm{C}$ difficile is uncertain but compelling. Of particular interest is the role of vancomycin or metronidazole therapy in the development of new isolates of Yersinia species in four patients reported here. This seemed to be especially associated with persisting or recurrent diarrhea.

Clinical differentiation of patients with and without yersinia in the presence of $\mathrm{C}$ difficile appears to be difficult. Abdominal pain was more common with yersinia in the present study, but this symptom is well recognized in patients with $\mathrm{C}$ difficile colitis (18). Fever and bloody diarrhea were also present in both groups. Arthralgias, reported in up to $30 \%$ of patients with $Y$ enterocolitica infection $(19,20)$ also occurs in C difficile colitis (21-24) and could not predict the presence of Yersinia species in the present patients.

Yersinia enterocolitis has been associated with normal mucosa, nonspecific colitis and colonic mucosal aphthoid ulcerations (25), but in this study, sig- moidoscopic examination and rectal mucosal biopsy of patients with $\mathrm{C}$ difficile diarrhea could not differentiate between patients with and without yersinia coinfection. Pseudomembranes were seen in a minority of patients with and without yersinia. Two of the present patients, both having isolates of $C$ difficile and $Y$ enterocolitica, presented as an exacerbation of previously diagnosed inflammatory bowel disease; both C difficile (26-28) and yersinia $(3,29)$ have been implicated in this setting. Under these circumstances, morphologic diagnosis may be very difficult.

In summary, an inordinately high prevalence of Yersinia species exists in the stools of patients referred to the authors institution with post antibiotic $\mathrm{C}$ difficile colitis. Failed therapy of $\mathrm{C}$ difficile colitis may be associated with yersinia coinfection. Yersinia species, particularly $Y$ enterocolitica, must be considered potential enteric pathogens in the post antibiotic state and the confirmation of $\mathrm{C}$ difficile does not obviate the need to carefully seek their presence in this situation.

ACKNOWLEDGEMENTS: The authors thank Dr Sandu Toma of the National Reference Centre of Yersinia, Ontario Ministry of Health, Public Health Laboratories, Toronto, Ontario.

\section{REFERENCES}

1. Freeman HJ. Antibiotic-induced pseudomembranous colitis. New approaches. Drug Therapy 1985;15:117-30.

2. Walters BAJ, Roberts R, Stafford R, Seneviratone E. Relapse of antibiotic associated colitis. Endogenous persistence of Clostridium difficile during vancomycin therapy. Gut 1983;24:206-12.

3. Simmonds SD, Noble MA, Freeman HJ Gastrointestinal features of culturepositive Yersinia enterocolitica infection. Gastroenterology 1987;92:112-7.

4. Allen SD. Clostridium. In: Lennette EH, ed. Manual of Clinical Microbiology, 4th edn. Washington, DC: American Society of Microbiology, 1985:434-44.

5. Hummel RP, Altemeier WA, Hill E. Iatrogenic staphylococcal enterocolitis. Ann Surg 1964;138:551-60.

6. Borrielo SP, Larson HE. Enterotoxigenic Clostridium perfringens: A possible cause of antibiotic-associated diarrhea. Lancet 1984;i:305-7. 
7. Taylor NS, Thorne GM, Bartlett JG. Comparison of two toxins produced by Clostridium difficile. Infect Immun 1981:34:1036-43.

8. Lyerly DM, Lockwood DE, Richardson SH, Wilkins TD. Biological activities of toxins $\mathrm{A}$ and $\mathrm{B}$ of Clostridium difficile. Infect Immun 1982:35:1147-50.

9. Sullivan NM, Pellet S, Wilkins TD Purification and characterization of toxins $\mathrm{A}$ and $\mathrm{B}$ of Clostridium difficile. Infect Immun 1982;35:1032-40.

10. Burdon DW, George RH, Mogg G. Faecal toxin and severity of antibiotic-associated pseudomembranous colitis. J Clin Pathol 1981;34:548-51.

11. Justus PG, Martin JL, Goldberg DA. et al. Myoelectric effects of Clostridium difficile: Motility altering factors distinct from its cytotoxin and enterotoxin in rabbits. Gastroenterology 1982:83:836-43

12. Aronsson B, Mollby R, Nord CE. Antimicrobial agents and Clostridium difficile in acute enteric disease: Epidemiologic data from Sweden, 1980-82. J Infect Dis 1985; 151:476-81.

13. Nakamura S. Cytotoxin production by Clostridium sordellii strains. Microbiol Immunol 1983:27:495-502
14. Bartlett JG. Antibiotic associated colitis. Dis Mon 1984:30:1-54.

15. Falsen E, Kaijser B, Nehls L, Nygren B, Svedham A. Clostridium difficile in relation to enteric bacterial pathogens. J Clin Microbiol 1980;12:297-300.

16. Brittle RP. Wallace E. Clostridium difficile associated diarrhea. J Infection 1984:8:123-8

17. Brown R, Tedesco Fl. Assad RT, Rao R. Yersinia colitis masquerading as pseudomembranous colitis. Dig Dis Sci 1986:31:548-51

18. Mogg GM, Keighley M. Antibiotic associated colitis: A review of 66 cases. Br J Surg 1979;66:738-42.

19. Ahvonen P. Sievers K, Aho K. Arthritis associated with Yersinia enterocolitica infection. Acta Rheum Scand 1969:15:232-53.

20. Ahvonen P. Human yersiniosis in Finland. Il Clinical features. Ann Clin Res 1972:4:39-48.

21. Rollin DE, Moeller D. Acute migratory polyarthritis associated with antibioticinduced pseudomembranous colitis. Am J Gastroenterol 1976:65:353-6.

22. Rothchild BM, Masi AT, June PL. Arthritis associated with ampicillin colitis. Arch Intern Med 1977:135:1605-7.
23. Bolton RP, Wood GM, Losowsky MS. Acute arthritis associated with Clostridium difficile colitis. $\mathrm{Br}$ Med 1 1981;283:1023-4

24. Lofgren RP, Tadlock LM, Soltis RD, Acute oligoarthritis associated with Clostridium difficile pseudomembranous colitis. Arch Intern Med 1984:144:617-9.

25. Vantrappen G, Agg HO, Ponette E, Geboes K, Bertrand PH. Yersinia enteritis and enterocolitis: Gastroenterological aspects. Gastroenterology 1980;72:220-7.

26. La Mont IT, Trnka Y. Therapeutic implications of Clostridium difficile toxin during relapse of chronic inflammatory bowel disease. Lancet 1980;i:381-2.

27. Trnka YM, La Mont JT. Association of Clostridium difficile toxin with symptomatic relapse of chronic inflammatory bowel disease. Gastroenterology 1981:80:693-6.

28. Meyers S, Mayer L, Bottone E, Desmond $E$. Janowitz $H D$. Occurrence of Clostridium difficile toxin during the course of inflammatory bowel disease. Gastroenterology 1981;80:697-700.

29. Treacher DF, Jerwell DP. Yersinia colitis associated with Crohn's disease Postgrad Med J 1985;61:173-4 


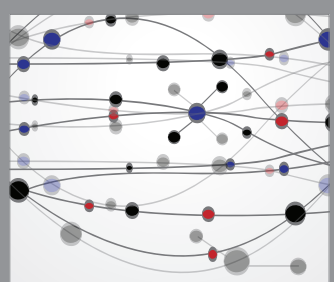

The Scientific World Journal
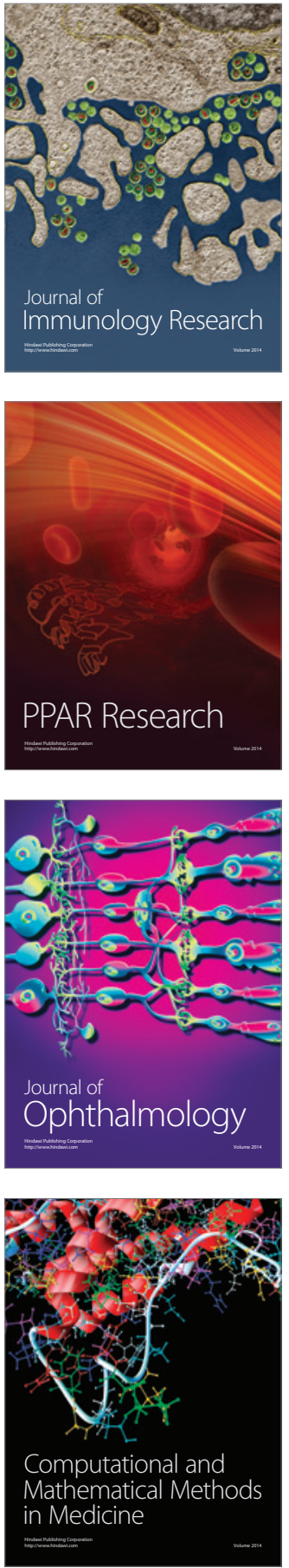

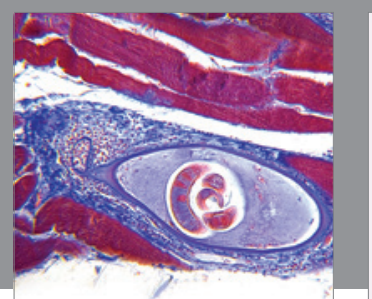

Gastroenterology Research and Practice

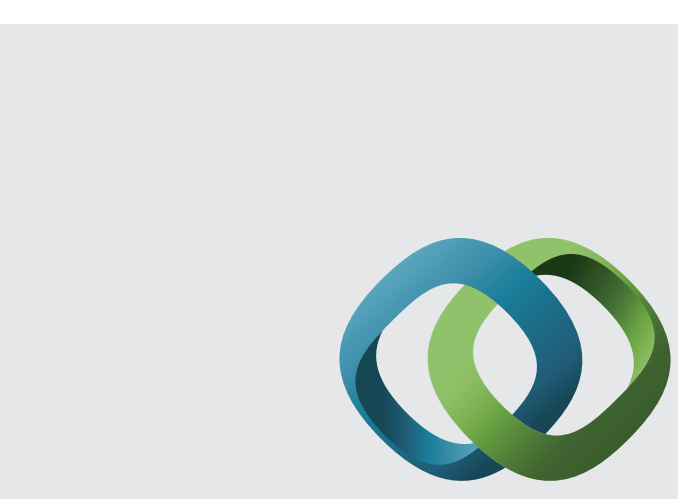

\section{Hindawi}

Submit your manuscripts at

http://www.hindawi.com
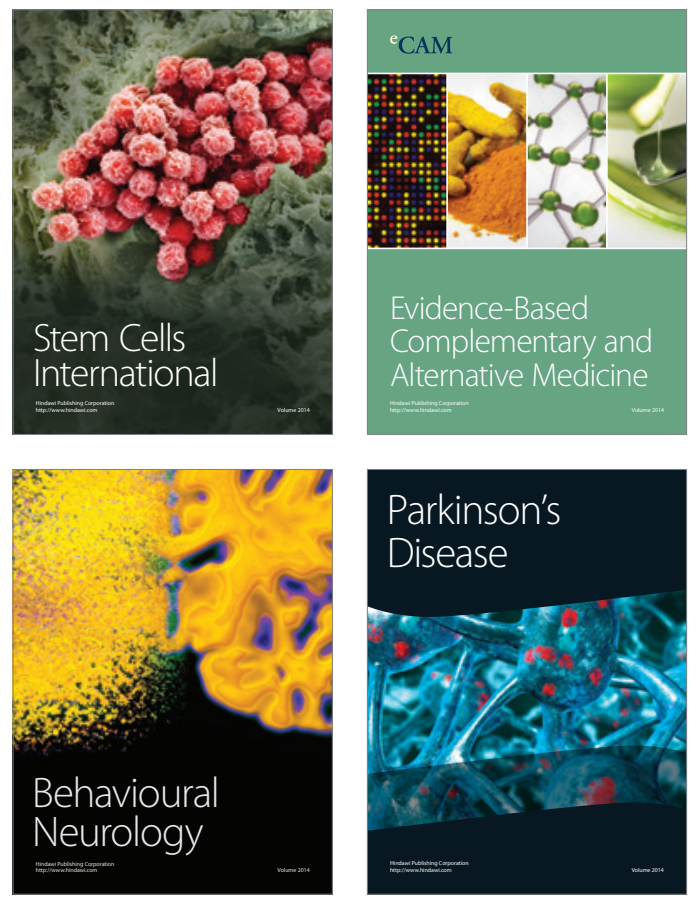
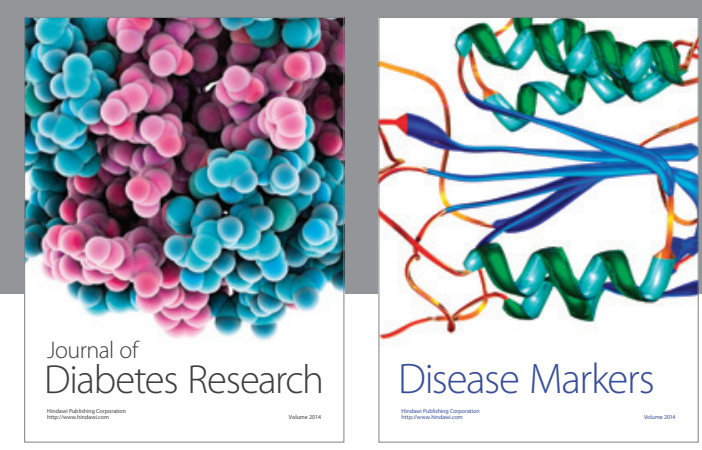

Disease Markers
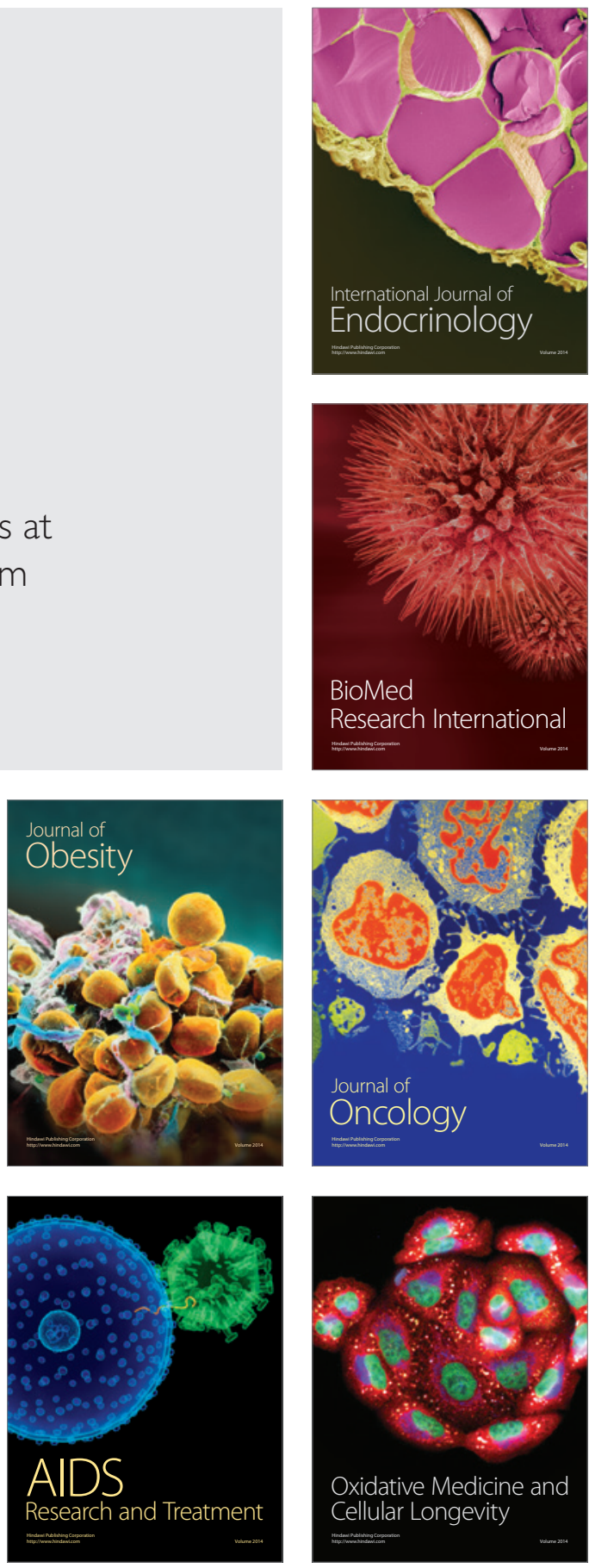